\title{
First Pregnancy, Somatic and Psychological Status of a 4-Year-Old Child Born following Annexin V TESA Sperm Separation
}

\author{
Krzysztof Lukaszuk 1,2,3,4 Monika Wcislo, PhD ${ }^{2}$ Joanna Liss, PhD ${ }^{1}$ Anna Stachowicz, PhD ${ }^{4}$ \\ Grzegorz Jakiel ${ }^{4}$ Mariusz Lukaszuk, $\mathrm{PhD}^{1}$ Ewa Pastuszek, $\mathrm{PhD}^{1,3} \quad$ Izabela Woclawek-Potocka ${ }^{5}$ \\ Antonio Galvao, $\mathrm{PhD}^{5}$ Dorota Bialobrzeska, $\mathrm{PhD}^{1}$
}

${ }^{1}$ INVICTA Fertility and Reproductive Centre, Gdańsk, Poland

2 INVICTA Fertility and Reproductive Centre, Warsaw, Poland

${ }^{3}$ Department of Obstetrics and Gynecological Nursing, Medical University of Gdansk, Gdańsk, Poland

${ }^{4}$ Department of Obstetrics and Gynaecology, The Medical Center of Postgraduate Education, Warsaw, Poland

${ }^{5}$ Department of Reproductive Immunology and Pathology, Institute of Animal Reproduction and Food Research, Olsztyn, Poland
Address for correspondence Krzysztof Lukaszuk, INVICTA Fertility and Reproductive Centre, Rajska 10, 80-850 Gdansk, Poland (e-mail: krzysztof.lukaszuk@invicta.pl).

Am J Perinatol Rep 2015;5:e105-e108.

\begin{abstract}
Keywords

- sperm

- testicular sperm aspiration

- intracytoplasmic sperm injection

- sperm DNA integrity

Introduction Sperm DNA integrity is a crucial paternal factor affecting fertilization and pregnancy rates, as well as embryo development.

Case The present case report describes the successful pregnancy after testicular sperm aspiration (TESA) combined with intracytoplasmic sperm injection (ICSI) (TESAICSI) in a couple where the male presented high sperm DNA fragmentation. In order to sort damaged sperm presenting DNA fragmentation, magnetic activated cell sorting (MACS) with annexin $V$ microbeads (MACS Miltenyi Biotec, Teterow, Germany) was used.

Conclusion The authors present the first description of a successful medical case using TESA-ICSI annexin V sperm sorting. Additionally, a follow-up of the child at the age of 4 years old was done.
\end{abstract}

Fertility success is highly dependent on disorders of the male reproductive system. It is well established that spermatozoa from infertile men present structural and functional defects. ${ }^{1}$ Expressly, sperm DNA integrity determines the normal embryo development. The main mechanisms of DNA damage in spermatozoa include the following: (1) apoptosis during the process of spermatogenesis ${ }^{2}$; (2) DNA strand breaks produced during remodeling of sperm chromatin ${ }^{3}$; and (3) posttesticular DNA fragmentation induced by oxygen radicals. ${ }^{4}$ In addition, DNA fragmentation can also be induced by endogenous caspases, endonucleases, as well as external factors such as radiotherapy, chemotherapy, and environmental toxicants. ${ }^{3,4}$ The integrity of sperm DNA influences fertility and helps to predict chances of pregnancy and its successful outcome. ${ }^{4}$ A high level of DNA fragmentation leads to the lower fertilization rate, ${ }^{5,6}$ poor embryo cleavage-the paternal genome is switched on, as well as subsequent blastocyst development. ${ }^{7,8}$ Moreover, sperm DNA fragmentation is also correlated with both pregnancy and miscarriage rates. ${ }^{9-13}$ To reduce the number of DNA-damaged spermatozoa, numerous strategies can be applied before ICSI treatment, such as, (1) appropriate sperm preparation ${ }^{3,14}$; (2) in vivo or in vitro antioxidant treatment ${ }^{15,16}$; and (3) and magnetic cell separation. ${ }^{17-20}$ Magnetic-activated cell sorting (MACS) is rapid, convenient, and noninvasive method. This method using paramagnetic annexin V-conjugated received

November 5, 2014 accepted after revision

February 12, 2015

published online

April 6, 2015
Dol http://dx.doi.org/

10.1055/s-0035-1548726. ISSN 2157-7005.
Copyright (c) 2015 by Thieme Medical Publishers, Inc., 333 Seventh Avenue, New York, NY 10001, USA. Tel: +1(212) 584-4662.
License terms

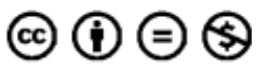


microbeads is the only known technique which separates apoptotic spermatozoa from nonapoptotic spermatozoa. MACS acts at the molecular level as opposed to routine sperm preparation techniques that rely on sperm density and motility. During apoptosis, phosphatidylserine residues are translocated from the inner membrane of the spermatozoa to the outside. Annexin V has a strong affinity for phosphatidylserine but cannot pass through the intact sperm membrane. Therefore, in this study, this innovative medical approach based on MACS with annexin V microbeads was used to identify and exclude semen presenting signals of apoptosis or damaged membrane.

\section{Patients and Methods}

\section{Female Hormonal Protocol}

A young Polish couple (female 26 years old and partner 28 years old) from western Poland was referred to the Invicta Fertility Clinic, seeking for infertility treatment. The woman was considered fertile, as she had a child with her previous partner. Nevertheless, a full hormonal diagnosis (results shown in - Table 1) was performed. After the initial ultrasonographic antral follicular count assessment, a long protocol with human menopause gonadotropin (HMG, Menopur, Ferring Pharmaceuticals Inc., Saint-Prex, Switzerland) in association with the short-acting GnRH analog was started: $225 \mathrm{IU}$ for 4 days and $150 \mathrm{IU}$ for the next 3 days, followed by $225 \mathrm{IU}$ for the subsequent 3 days. The HMG dose was estimated according to our protocol of stimulation, which is based on AMH level. ${ }^{21}$ Because of the unsuccessful pregnancy after the first protocol, a new treatment was performed. This stimulation lasted 1 day longer than the previous one and extra 150 IU of Menopur were used.

\section{Testicular Sperm Aspiration, Sperm Quality}

\section{Assessment, and Magnetic-Activated Cell Sorting}

The male was handicapped because of a traffic accident, which resulted in paraplegia without any chance of intercourse. To reduce the DNA fragmentation, before testicular sperm aspiration (TESA), the patient received an in vivo antioxidant treatment for 3 months. After TESA, the level of DNA fragmentation was measured by the terminal deoxynucleotidyl transferase dUTP nick end labeling (TUNEL) assay (System, TB235, Promega, Madison, WI), following the manufacturer's instructions. Further on, MACS with annexin V microbeads (MACS Miltenyi Biotec) was performed. The technique consists in the ability of superparamagnetic annexin $\mathrm{V}$ microbeads to bind externalized phosphatidylserine on the outer layer of the plasma membrane of sperm with activated apoptosis signaling or membrane damage. Sperm isolated by TESA after separation by MACS annexin V microbeads was used for intracytoplasmic sperm injection (ICSI) (TESA-ICSI). Briefly, a $100 \mu \mathrm{L}$ sperm sample was mixed with $100 \mu \mathrm{L}$ of MACS microbeads and incubated at room temperature for 15 minutes. The mixture was loaded on top of the separation column, which was placed in the magnetic field. The column was rinsed with buffer. All the unlabeled (annexin $\mathrm{V}$-negative) nonapoptotic spermatozoa passed through the column. The annexin $\mathrm{V}$-positive (apoptotic) fraction was retained in the column. The column was removed from the magnetic field, and annexin $\mathrm{V}$-positive fraction was eluted using the annexin V-binding buffer. Spermatozoa prepared by density gradient centrifugation followed by MACS had a higher percentage of motility, higher percentage viability, and a lower expression of apoptotic markers than spermatozoa prepared by density gradient centrifugation alone. Both in vitro fertilization (IVF) and embryo transfer (ET) (IVF-ET) procedures were conducted as previously described. ${ }^{22}$

\section{Assessment of Child's Psychomotor Development}

To assess the psychomotor development of the child at the age of 3 years 9 months and 20 days, the Leiter International Performance Scale P-93 was employed ${ }^{23}$ along with clinical tests based on the literature review. ${ }^{24-27}$ The Leiter International Performance Scale basically represents a test of fluid intelligence.

After adequate patient counselling, the consent form approved by the review board of the institutional Ethics Committee was signed.

Table 1 Hormonal profile of the female patient ${ }^{a}$

\begin{tabular}{|l|l|l|}
\hline Factor & Observed level & Reference level \\
\hline Anti-Mullerian hormone & $3.9 \mathrm{ng} / \mathrm{mL}$ & $>1.4 \mathrm{ng} / \mathrm{mL}$ \\
\hline Inhibin B & $47.5 \mathrm{pg} / \mathrm{mL}$ & $>20 \mathrm{pg} / \mathrm{mL}$ \\
\hline Oestradiol & $46.9 \mathrm{pg} / \mathrm{mL}$ & $20-160 \mathrm{pg} / \mathrm{mL} \mathrm{during} \mathrm{FP}$ \\
\hline Luteinizing hormone & $4.42 \mathrm{mIU} / \mathrm{mL}$ & $1.1-11.6 \mathrm{mIU} / \mathrm{mL} \mathrm{during} \mathrm{FP}$ \\
\hline Follicle-stimulating hormone & $8.15 \mathrm{mIU} / \mathrm{mL}$ & $2.8-11.3 \mathrm{mIU} / \mathrm{mL} \mathrm{during} \mathrm{FP}$ \\
\hline Prolactin (metoclopramide $60 '$ stimulation test) & $210 / 3180 \mathrm{mIU} / \mathrm{L}$ & $40-530 \mathrm{mlU} / \mathrm{L}$ \\
\hline Testosterone & $0.953 \mathrm{nmol} / \mathrm{L}$ & $<2.8 \mathrm{nmol} / \mathrm{L}$ \\
\hline Thyroid-stimulating hormone & $0.792 \mathrm{uU} / \mathrm{mL}$ & $0.4-4 \mathrm{uU} / \mathrm{mL}$ \\
\hline Antithyroid peroxidase antibodies & $12.2 \mathrm{IU} / \mathrm{mL}$ & $<35 \mathrm{IU} / \mathrm{mL}$ \\
\hline Sex hormone-binding globulin & $46.3 \mathrm{nmol} / \mathrm{L}$ & $18-114 \mathrm{nmol} / \mathrm{L}$ \\
\hline
\end{tabular}

aEarly follicular phase (FP). 


\section{Results}

The woman presented an adequate hormonal profile ( - Table 1). In the first clinical protocol, 13 cumulus-oocyte complexes (COCs) were retrieved, and 6 of them in matured metaphase II oocytes (MII) oocytes were injected (first ICSI-TESA). Afterward, five oocytes showed normal fertilization, confirmed by the presence of two pronuclei. Until the day 3, all embryos presented normal in vitro development; however, on the day 4 , three of the embryos stopped to develop. On day 5, two poor-quality blastocysts were transferred. The patient received oral progestagens to support the luteal phase with no effect on the conception. This unsuccessful approach determined the implementation of the second protocol.

Because of the high level of DNA fragmentation, 59.26\% measured by the terminal deoxynucleotidyl transferasedUTP nick end labeling (TUNEL) assay (-Fig. 1), and poor embryo development after the first approach,the authors decided to use MACS with annexin V microbeads (MACS Miltenyi Biotec).

For the second protocol, the couple started their second ICSI-TESA program. A total of 11 follicles were identified when counting the antral follicles ultrasonographically. Overall, 10 COCs were collected and 6 MII oocytes were found. Sperm isolated by TESA after separation by MACS annexin $\mathrm{V}$ microbeads was used for microinjection. Four oocytes showed normal fertilization, and three embryos developed properly until 72 hours of in vitro culture. On day 5 , one good-quality embryo was transferred, once the remaining two presented poor-quality embryos. After 11 days of standard luteal phase supplementation, the HCG was determined and presented the level of $197 \mathrm{mIU} / \mathrm{mL}$. One week later, the gestational sac was found. The second trans-

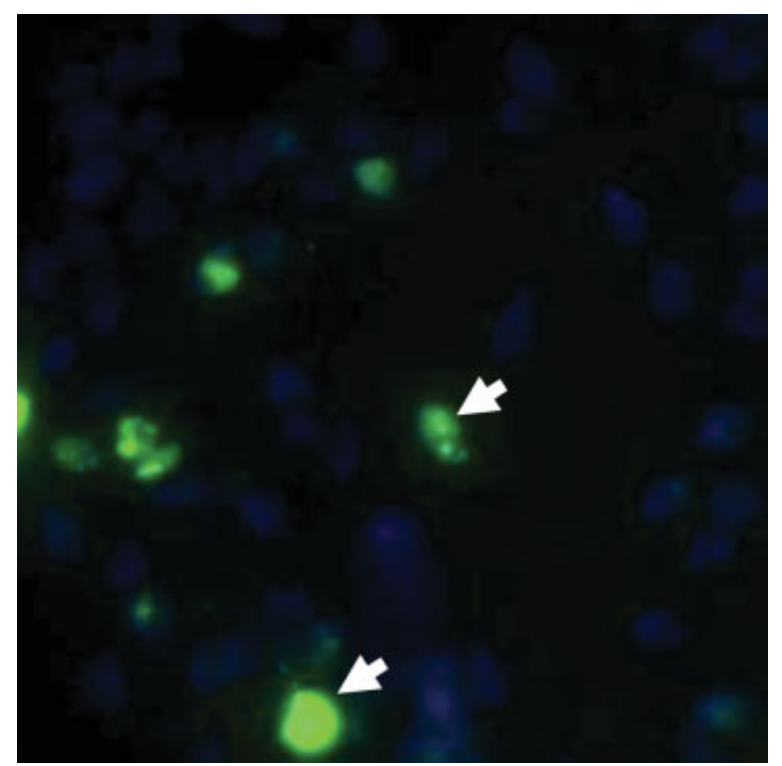

Fig. 1 Detection of apoptosis in spermatozoa using TDT-mediated dUTP nick end labeling (TUNEL) assay. Localized green fluorescence of apoptotic tissue assessed by confocal fluorescence microscopy (white arrow). DAPI (4', 6-diamidino-2-phenylindole)-stained nuclei presented in blue. vaginal ultrasound performed 7 days later revealed one normal inserted gestational sac with the presence of an embryo and normal cardiac activity. No complications were observed during the pregnancy. A healthy baby with $3,450 \mathrm{~g}$ body weight was delivered by cesarean section on week 38 of pregnancy. The baby presented a normal Apgar score and did not require any life support. Presently, the boy is alive and no major or minor congenital malformations have been observed. The auxological parameters, and proper mental and psychomotor development have been observed for the past 4 years.

Assessment of the child's development did not reveal any abnormalities, confirming the safety of the method used. The child's raw score was 13 points, which represents a $95 \%$ probability of lying between 10 and 16 points in the referred scale. This corresponds to a 108 to 136 level on the intelligence quotient (IQ) scale, corresponding subsequently to a $85 \%$ of confidence that the value is between 112 and 131 points on the IQ scale (standardization for polish children aged 3.6-3.11). The child's score belongs to average, high, and very high results at both confidence levels. These results demonstrate that the child accurately completed perception tasks, performed sight synthesis and analysis, and comprehended symbols. On the basis of the clinical tests and psychological observations, right laterality was determined, as well as age-adequate fine and gross motor skills, verbal abilities, cognitive development, and personal-social development.

\section{Discussion}

The DNA fragmentation index (DFI) is currently accepted as the selection marker for assisted reproductive technology (ART) methods. Our study provides an opportunity to improve ART methods based on DFI. Presently, the most important problem in ICSI seems to be the in vivo selection of sperm. ${ }^{28}$ Indeed, while treating infertility, there is no ideal marker for monitoring and selecting the best sperm. It may be a crucial problem regarding TESA sperm or extremely poor semen. To the best of our knowledge, the separation of sperm by MACS presented in this work was used for the first time. It has been evidenced that sperm DNA fragmentation is a determinant factor to be taken into consideration while evaluating male infertility. MACS binding apoptotic spermatozoa can reduce the level of sperm DNA fragmentation before ICSI treatment. Our findings confirm previous data from the year 2010, which showed that MACS annexin V microbeads were useful for the treatment of couples with high-sperm DNA fragmentation. ${ }^{18,29}$ As sperm DNA damage has been associated with an increased risk of pregnancy loss, due to MACS annexin V microbeads utilization, we can improve the live birth rate and optimize sperm selection in assisted reproduction before ICSI execution. The boy who was born after using the sperm separation was examined when he was 4 years old. His psychological and somatic scores belong to average, high, and very high results, which could prove the usefulness and safety of the method; however, the analysis of a larger number of patients is needed. 


\section{Disclosure Summary}

The authors have nothing to disclose.

Conflicts of Interest

The authors declare no conflicts of interests.

\section{Author Contributions}

K. L., M. W., J. L., M. L., A. S., and E. P. acquired the data, K. L., G. J., and D.B. designed the study, K. L., M. W., A. G., and I. W. -P. wrote the article, and all the authors critically reviewed and approved the final manuscript.

\section{References}

1 Lui SC, Weaver SM, Robinson J, et al. A survey of semen donor attitudes. Hum Reprod 1995;10(1):234-238

2 Shukla KK, Mahdi AA, Rajender S. Apoptosis, spermatogenesis and male infertility. Front Biosci (Elite Ed) 2012;4:746-754

3 Agarwal A, Said TM. Role of sperm chromatin abnormalities and DNA damage in male infertility. Hum Reprod Update 2003;9(4): 331-345

4 Sakkas D, Alvarez JG. Sperm DNA fragmentation: mechanisms of origin, impact on reproductive outcome, and analysis. Fertil Steril 2010;93(4):1027-1036

5 Kefer JC, Agarwal A, Sabanegh E. Role of antioxidants in the treatment of male infertility. Int J Urol 2009;16(5):449-457

6 Sikka SC. Role of oxidative stress and antioxidants in andrology and assisted reproductive technology. J Androl 2004;25(1):5-18

7 Janny L, Menezo YJR. Evidence for a strong paternal effect on human preimplantation embryo development and blastocyst formation. Mol Reprod Dev 1994;38(1):36-42

8 Ward WS. Function of sperm chromatin structural elements in fertilization and development. Mol Hum Reprod 2010;16(1):30-36

9 Bakos HW, Thompson JG, Feil D, Lane M. Sperm DNA damage is associated with assisted reproductive technology pregnancy. Int J Androl 2008;31(5):518-526

10 Robinson L, Gallos ID, Conner SJ, et al. The effect of sperm DNA fragmentation on miscarriage rates: a systematic review and meta-analysis. Hum Reprod 2012;27(10):2908-2917

11 Simon L, Brunborg G, Stevenson M, Lutton D, McManus J, Lewis SEM. Clinical significance of sperm DNA damage in assisted reproduction outcome. Hum Reprod 2010;25(7):1594-1608

12 Zhang L, Wang L, Zhang X, et al. Sperm chromatin integrity may predict future fertility for unexplained recurrent spontaneous abortion patients. Int J Androl 2012;35(5):752-757
13 Zini A, Boman JM, Belzile E, Ciampi A. Sperm DNA damage is associated with an increased risk of pregnancy loss after IVF and ICSI: systematic review and meta-analysis. Hum Reprod 2008; 23(12):2663-2668

14 Muratori M, Maggi M, Spinelli S, Filimberti E, Forti G, Baldi E. Spontaneous DNA fragmentation in swim-up selected human spermatozoa during long term incubation. J Androl 2003;24(2): 253-262

15 Agarwal A, Nallella KP, Allamaneni SSR, Said TM. Role of antioxidants in treatment of male infertility: an overview of the literature. Reprod Biomed Online 2004;8(6):616-627

16 Shafik A, Shafik AA, Shafik I, El Sibai O. Sperm DNA fragmentation. Arch Androl 2006;52(3):197-208

17 Glander HJ, Schaller J. Binding of annexin V to plasma membranes of human spermatozoa: a rapid assay for detection of membrane changes after cryostorage. Mol Hum Reprod 1999;5(2):109-115

18 Nasr-Esfahani MH, Deemeh MR, Tavalaee M. New era in sperm selection for ICSI. Int J Androl 2012;35(4):475-484

19 Rawe VY, Boudri HU, Alvarez Sedó C, Carro M, Papier S, Nodar F. Healthy baby born after reduction of sperm DNA fragmentation using cell sorting before ICSI. Reprod Biomed Online 2010;20(3): 320-323

20 Said T, Agarwal A, Grunewald S, et al. Selection of nonapoptotic spermatozoa as a new tool for enhancing assisted reproduction outcomes: an in vitro model. Biol Reprod 2006;74(3):530-537

21 Lukaszuk K, Liss J, Kunicki M, et al. Anti-Müllerian hormone (AMH) is a strong predictor of live birth in women undergoing assisted reproductive technology. Reprod Biol 2014;14(3):176-181

22 Lukaszuk K, Liss J, Lukaszuk M, Maj B. Optimization of estradiol supplementation during the luteal phase improves the pregnancy rate in women undergoing in vitro fertilization-embryo transfer cycles. Fertil Steril 2005;83(5):1372-1376

23 Jaworowska AMA, Szustrowa T. Leiter International Performance Scale P-93. Polish 1993 Standardisation. Psychological Test Laboratory Polish Psychological Association, Warsaw; 1993

24 Bee H. Psychologia rozwoju człowieka. 2004. Zysk i S-ka, Poznań

25 Vasta R, Haith MM, Miller SA. Psychologia dziecka. 2004. WSiP, Warsaw

26 Schaffer RH. Psychologia dziecka. 2011. WN PWN, Warsaw

27 Brazelton TB, Sparrow JD. Rozwój dziecka. Od 3 do 6 lat. 2013. GWP, Sopot

28 Oleszczuk K, Augustinsson L, Bayat N, Giwercman A, Bungum M. Prevalence of high DNA fragmentation index in male partners of unexplained infertile couples. Andrology 2013; 1(3):357-360

29 Polak de Fried E, Denaday F. Single and twin ongoing pregnancies in two cases of previous ART failure after ICSI performed with sperm sorted using annexin V microbeads. Fertil Steril 2010; 94(1):351.e15-351.e18 